\title{
O espelho partido de Oscar Wilde*1
}

\author{
Marcus Rodrigues Jacobina Vieira*2 \\ Elisa Maria de Ulhôa Cintra*3
}

Este artigo tece algumas considerações a respeito dos processos de luto e melancolia, dos desafios que surgem à elaboração de lutos e perdas. Foi inspirado na teoria psicanalítica e na leitura de alguns aspectos da vida de Oscar Wilde extraídos de sua biografia, escrita por Daniel Salvatore Schiffer, para iluminar a mesma problemática de inibição do luto, conduzindo à melancolia e ao empobrecimento da criatividade.

Palavras-chave: Luto, melancolia, posição depressiva, objeto interno, Klein

*1 O artigo baseia-se na dissertação de mestrado intitulada Oscar Wilde e Dorian Gray: sobre a experiência da perda, da dor e do luto. Vieira, M. R. J. (2014). Programa de Psicologia Clínica, Pontifícia Universidade Católica de São Paulo PUC-SP, São Paulo, orientada pela Profa. Elisa Maria de Ulhôa Cintra.

*2 Doutorando no Programa de Estudos Pós-Graduados em Psicologia Clínica da Pontifícia Universidade Católica de São Paulo - PUC-SP (São Paulo, SP, Br).

*33 Pontifícia Universidade Católica de São Paulo - PUC-SP (São Paulo, SP, Br). 
A vida do escritor Oscar Wilde ficou tragicamente marcada pelo advento de sua condenação e prisão no ano de 1895, eventos que lançaram uma pesada sombra sobre os seus sucessos anteriores, levando-o, mesmo depois de libertado, a se perceber destituído de sua genialidade e talento criativo.

De acordo com Schiffer (2011), certo tempo antes de sua prisão, o escritor viveu um relacionamento tumultuado e passional com o jovem lorde Alfred Douglas, conhecido como Bosie, o que muito desagradou ao pai deste, o marquês de Queensberry, que não mediu esforços para que o filho rompesse a relação, chegando a insultar Wilde publicamente, que, incitado pelo amante, decide mover um processo por difamação contra o marquês.

No entanto, durante a ausência de Wilde, que parte em uma viagem com Bosie, Queensberry consegue reunir provas suficientes para incriminar o escritor, uma vez que nessa época a homossexualidade era considerada crime na Inglaterra. Condenado por flagrante indecência, Wilde cumprirá dois anos de trabalhos forçados em diversas prisões inglesas e, quando libertado, cairá em desgraça, ao se dar conta de sua impossibilidade de retomar o trabalho criativo.

Cabe ressaltar que, mesmo depois dessa traumática experiência, Wilde alimentava o projeto de dar continuidade a seu ofício; ainda que se sentisse, de início, pouco inspirado a escrever, não desacreditou que o estado de alma necessário para fazê-lo retornaria.

Porém, aos poucos e com muito pesar e sofrimento, Wilde perceberá que sua potência criadora lhe fora arrancada. E mais, ao passar em revista a própria vida, será obrigado a reconhecer que, apesar de sua trajetória como defensor do hedonismo, e sobretudo do individualismo, necessitava do outro para recuperar sua capacidade de escrever. Descobrirá, após um período de buscas 
infrutíferas no sentido de encontrar, através das suas parcerias afetivas, condições que o estimulassem a criar, que a principal condição para dar continuidade à sua arte e à sua criatividade - a alegria de viver havia se perdido completamente.

Após os dois anos em que esteve enclausurado, exilado e privado do mundo de arte e beleza do qual se julgava parte, humilhado e despojado de seu antigo estilo de vida, sem o direito de ver os filhos e sem a glória e a audiência que o consagraram como o apóstolo da beleza, Wilde sente-se castrado, como se o tempo na prisão o tivesse amputado, causando uma espécie de fratura em seu psiquismo. Por sua correspondência na época, fica claro que não possuía condições internas de processar todas as perdas sofridas com tamanha violência.

Uma vez do lado de fora das prisões em que cumpriu pena, Wilde parece carregá-las dentro de si. Essa prisão interior, muito mais eficaz em seu poder de bloquear e destruir subjetividades, tornou-se o lugar de onde ele jamais conseguiu escapar.

Pensemos na magnitude do trauma que foi a experiência da prisão, a humilhação pública e o desprezo recebido daquela mesma sociedade que admirava a sua genialidade, na violência da ruptura com a vida de antes, com os valores celebrados por Wilde, que se dedicava a tornar bela a própria existência, transformando-a em uma obra de arte. Por que Wilde, depois de ter vivido todas as perdas possíveis a um artista célebre como ele o foi, não conseguiu transpor a barreira que se estabeleceu entre ele e sua arte? Por que não conseguiu atravessar a ponte na direção de uma subjetividade renovada, ou mesmo, não foi capaz de usar a experiência de sofrimento vivido na prisão transformando-a em algo criativo?

A imagem da travessia da ponte, que simboliza o elo entre dois pontos distintos e que aqui podemos pensar como a ligação entre passado e futuro, a transição entre o ideal e o real, nos remete a um trecho do livro A história sem fim do escritor Michael Ende (2010) e que julgamos pertinente para nossa discussão.

O romance narra as aventuras de Atreiú, um jovem caçador que é designado pela imperatriz Criança do mítico Reino de Fantasia para empreender aquilo que chamam de "a grande busca". A imperatriz Criança está muito doente e ninguém conseguiu descobrir nem a causa nem a cura para sua enfermidade. Além dessa tragédia, a doença da imperatriz coincide com a ameaça do aniquilamento de todo o reino, que poderá ser transformado em um mundo de sombras e vazio por uma força terrível e desconhecida. Atreiú deve encontrar as respostas que trarão de volta a saúde à imperatriz e a paz e segurança ao Reino de Fantasia.

Atreiú é muito corajoso e sai em sua busca na companhia de seu inseparável cavalo Artax. Ele leva consigo uma insígnia ofertada pela imperatriz Criança, chamada de Aurin ou "o Brilho" ou "a Joia", que lhe conferirá poder e o protegerá. A certa altura de sua jornada, Atreiú e Artax se encontram diante do Pântano da Tristeza, que devem atravessar. Artax demonstra temor e receio e, à 


\section{LITERATURA, PSICOPATOLOGIA}

medida que ambos nele penetram, o cavalo vai se atolando, sentindo grande dificuldade para vencer as águas pantanosas que parecem lhe tragar todas as forças. Em pouco tempo, sente-se paralisado e completamente impotente e desvitalizado, até o ponto de desistir da própria vida para que seu mestre consiga seguir adiante.

Numa cena tocante, acompanhamos o desespero de Atreiú, que, com todas as suas forças, tenta dissuadir Artax de sua desesperança, impelindo-o a resistir e insistir pela vida. Mas todas as palavras e tentativas do jovem caçador são em vão, e é chegado o momento da separação. Por que Atreiú parece imune aos malefícios do pântano enquanto Artax é invadido e tragado pela tristeza que dá nome ao lugar? Talvez a resposta nos seja dada pelos próprios personagens em seu último diálogo.

Nenhum de nós sabia o que nos esperava aqui. Mas já sabemos por que o Pântano da Tristeza tem esse nome. É a tristeza, o que me torna tão pesado e que me faz afundar. Não é possível evitá-lo. Atreiú retruca argumentando que ele também está ali e que não sente nada. Artax lhe responde: "É porque você tem o Brilho e ele o protege". (Ende, 2010, p. 55)

Ter o "Brilho"! Por enquanto, vamos ficar com essa ideia guardada para retomá-la mais adiante...

Podemos refletir sobre as dificuldades e os conflitos que envolvem a necessidade de se abandonar uma posição anterior - sentida como prazerosa, ou pelo menos segura ou conhecida - , deixar o passado para seguir na direção do futuro desconhecido. A recusa em atravessar e a impossibilidade de completar a travessia nos reconduzem ao tormento de Oscar Wilde em seus últimos anos de vida.

Parece-nos que, de alguma forma, o escritor se negou a aceitar que todo o antes de sua vida já havia passado, tornando-se, portanto, irrecuperável, e mais ainda, que se fazia necessário despedir-se do antigo Wilde, integrando as experiências de sofrimento ao seu talento criativo. Mas ele não conseguiu transformar sua experiência de dor e sofrimento em narrativa e entrar no processo de luto e elaboração psíquica que envolve lembrar e narrar para transformar. Para compreender a importância do trabalho do luto na constituição do psiquismo devemos revisitar os postulados de Melanie Klein

\section{Luto e Posição Depressiva: sobre a capacidade de elaborar perdas e traumas}

Para Klein (1935/1996; 1940/1996) a elaboração da posição depressiva só é possível se houver a criação de um ambiente psíquico em que predominam as relações de amor e gratidão. Para isto, é preciso internalizar o bom objeto, ou seja, 
as experiências de prazer, satisfação, proteção, conforto e segurança, formando um registro, uma espécie de reserva interna a que o próprio indivíduo poderá recorrer continuamente e sempre que passar por experiências de privação, dor e sofrimento. É a esse processo que se dá o nome de firme internalização do bom objeto. Guardar essa marca na memória inconsciente propicia na criança e no adulto, no decorrer de toda a vida, um acesso ao prazer e à segurança, capacitando-os a tolerar estados transitórios de frustração e desprazer.

O objeto bom é, assim, o nome da experiência de satisfação introjetada e convertida em uma fonte de bem-estar e segurança, é o nome do que resulta da introjeção da experiência de encontro entre a necessidade da criança e o que o ambiente pôde efetivamente proporcionar a ela. Esse objeto bom introjetado será a fonte das pulsões de vida e amor. (Cintra \& Figueiredo, 2004, p. 84)

É durante a elaboração da posição depressiva que nasce a possibilidade de conter e elaborar a realidade psíquica; por isso, essa é uma posição tão importante para o desenvolvimento psíquico e para a criação da capacidade de amar e reparar. Seu funcionamento pode ser comparado a uma gestação, o que supõe a necessidade de dar tempo para que os elementos se ajustem satisfatoriamente entre si e na relação com o meio externo, pois é por meio desse trabalho de elaboração que se constitui o sujeito psíquico. Isto exige deixar passar o passado e fazer nascer um tempo presente que se abre a um futuro: cria-se um mundo interno de objetos e impulsos bons e maus que se formam pela integração dos impulsos ambivalentes (Hinshelwood, 1992, p. 154).

A saúde psíquica e a capacidade de amar e reparar dependem, substancialmente, da elaboração da posição depressiva; isto é, da maneira de lidar com a ambivalência fundamental, conseguindo-se, por fim, que prevaleçam os impulsos amorosos sobre o ódio. A satisfatória elaboração da posição depressiva

(...) cria algo como um "espaço psíquico" onde os conflitos poderão ser enfrentados, elaborados (ou perlaborados, como queria Freud, o que significa "ser atravessados"). Pensamos que podemos associar a posição depressiva a uma dinâmica gestacional: à ideia de processo e de temporalização; à ideia de trabalho que leva à moderação e à relativização da intensidade do prazer e do desprazer; e a um aumento da capacidade de considerar a realidade psíquica e a realidade externa. Por outro lado a posição paranoide fica associada às situações de gratificação e frustração intensas e imediatas, às operações defensivas radicais que envolvem rápidas oscilações entre tudo e nada, e bom e mau, absolutos. (Cintra \& Figueiredo, 2004, p. 90)

Tais considerações a respeito da importância da posição depressiva na saúde psíquica do adulto e da criança nos levam a pensar nas angústias e no trauma psíquico vivido por Oscar Wilde durante seus últimos anos de vida. Pensamos que 


\section{LITERATURA, PSICOPATOLOGIA}

o fato de não ter renunciado aos ideais de perfeição e beleza absolutos pode ter sido um impedimento severo da capacidade do escritor de elaborar satisfatoriamente seu sofrimento.

Em 1940, Melanie Klein amplia substancialmente o conceito de posição depressiva e a compreensão dos entraves e impedimentos que podem surgir durante seu atravessamento através de um texto intitulado "O luto e suas relações com os estados maníaco-depressivos", que estabelece uma conexão entre a posição depressiva e os processos de luto normal. $\mathrm{O}$ grande trabalho da posição depressiva é a elaboração das angústias psicóticas, o que envolve o tempo de uma infância inteira, e que deixa sempre algo a ser terminado pelo resto da vida. O trabalho de transformar ansiedades paranoides em ansiedades depressivas criará a base para o surgimento do sentimento de amor, culpa e do desejo de reparação do objeto amado. Quando há maior integração de impulsos libidinais e agressivos, essa ordenação é sentida como uma vitória contra o sentimento de caos interior.

Durante toda a infância, a criança enfrenta um longo processo de aprender a se separar dos pais, para conquistar uma autonomia psíquica e uma identidade própria. Nesse trajeto, precisa abrir mão de inúmeras idealizações, sobretudo dos pais ideais, sonhos de perfeição pessoal, que representam o desejo de ser capaz de realizar tudo, assim como uma parte da sua onipotência, os amores ideais e as fantasias de realização de plenitude e do absoluto.

"Os ídolos e os ideais precisam morrer e renascer modificados", nos dizem Cintra \& Figueiredo (2004, p. 92), e prosseguem afirmando que "a transitoriedade de tudo obriga, constantemente, a fazer o luto do momento presente para obter acesso ao momento seguinte" (p. 92).

Pensamos que a dificuldade de fazer luto dos ideais da infância, sobretudo do desejo de ser absolutamente perfeito, como um filho que procura ajustar-se, correspondendo exatamente às expectativas e exigências de seus genitores, pode ser um importante obstáculo para que se realize o trabalho psíquico de, justamente, fazer morrer esses pais da infância, comumente percebidos como ideais e perfeitos, assim como abrir mão das expectativas e exigências de perfeição sobre si mesmo.

Antes de ser julgado e condenado por "flagrante indecência", Wilde era um autor celebrado nas altas rodas da aristocracia da Londres do século XIX. Ao ter sua intimidade vasculhada e exposta publicamente, sofre um primeiro golpe, a condenação, para logo depois se ver destituído de tudo aquilo que sempre amou. A beleza e o florescimento de si, temas frequentemente interligados nos textos de Wilde antes da prisão, tornar-se-ão o referencial de uma vida que perdeu e à qual nunca mais terá acesso novamente, embora o deseje profundamente.

Wilde se apega de maneira aguerrida aos seus ídolos e ideais de outrora, negando-se, ainda que o estivesse fazendo sem perceber, a entrar num processo de 
luto pelo antigo Wilde, em que fosse possível chorar e sofrer profundamente pelas perdas sofridas e inaugurar uma nova etapa em sua criatividade artística.

Acreditamos também que a ideia de um mundo interno suficientemente povoado por bons objetos introjetados se relaciona com o conceito de espaço psíquico postulado por Pontalis (2005), já que a criação desse espaço nos parece ter uma forte conexão com o processo constitutivo da subjetividade.

Essa experiência primordial fundante está enraizada na experiência do desmame, que dá início a uma série de desdobramentos importantes para a constituição subjetiva do indivíduo. Trata-se de um primeiro e importante luto que ressignifica a cesura do nascimento, tornando possível a instalação do espaço psíquico, o que, por sua vez, está diretamente associado à firme introjeção do bom objeto. Esse profundo trabalho de elaboração psíquica constitui as bases para que o psiquismo desenvolva mecanismos que possibilitem lidar com as ansiedades de modo a suportar rupturas e traumatismos inescapáveis à experiência que é viver.

Pensamos essa constituição psíquica associada à instalação do objeto bom interno e ao atravessamento da posição depressiva, o que implica, necessariamente, elaborar de forma minimamente satisfatória o luto pelo objeto primário.

A introjeção do bom objeto se dá numa dinâmica que envolve a participação das dimensões intrapsíquicas e intersubjetivas. $\mathrm{O}$ nascimento e a vitalidade dessa subjetividade em desenvolvimento não se dão, apenas, a partir da economia pulsional, da disposição inata de cada indivíduo para a integração ou desintegração. É algo que depende fundamentalmente do encontro com outro ser humano, pelas trocas intersubjetivas que ocorrem nas relações mais arcaicas entre a mãe e o bebê.

Compreendemos que o indivíduo humano depende das trocas com o ambiente para compor seu mundo interno, de forma que as vivências de satisfação, proteção e segurança sejam preponderantes para que se instale o objeto bom interno, que aqui consideramos uma aproximação conceitual ao que Pontalis chama de espaço psíquico. A relação com o ambiente também promove a apreensão da realidade, o que, por seu turno, é fundamental para que o psiquismo em formação consiga ir discriminando, gradativamente, a realidade da fantasia.

Por considerar a importância dessa relação primordial que funda o espaço psíquico e o mundo interno do bebê, e como tributário dos postulados kleinianos, Pontalis (2005) afirma que a edificação desse espaço psíquico ou desse "quarto próprio", que aqui associamos à firme introjeção do objeto bom, está intrinsecamente relacionada ao trabalho do luto. Trata-se do luto da cena originária, que é despertado pela perda do objeto primário e que implica a entrada e o atravessamento da posição depressiva, com internalização do objeto bom interno. 


\section{LITERATURA, PSICOPATOLOGIA}

Ousamos também associar a firme introjeção do bom objeto ao elemento que no livro A história sem fim é chamado de o "Brilho", aquilo que protege e dá forças ao jovem herói Atreiú para atravessar todas as intempéries de sua jornada.

O "Brilho" descrito no livro é uma espécie de joia, uma insígnia que foi ofertada por outro, neste caso, a imperatriz Criança, mas que também poderia ser a figura da mãe ou de quem venha a exercer as funções de proteger e cuidar. Atreiú leva consigo algo que pertence e representa a própria imperatriz Criança, a soberana do reino de Fantasia. É o símbolo, a presença ausentemente disponível da imperatriz, o que nos faz lembrar de outro importante postulado defendido por Pontalis (2005), quando afirma que o espaço psíquico "é a mãe ausente que constitui o nosso interior" (p. 61).

Lembremos que, possivelmente, por ser possuidor do "Brilho", Atreiú não tenha sucumbido às tenebrosas forças que tragaram a vida do cavalo Artax para as profundezas do Pântano da Tristeza, durante sua travessia.

Isso nos faz pensar em todas as trocas intersubjetivas que se dão na relação da mãe com o bebê e que formam "o chão" da organização psíquica do indivíduo. Um mundo interno suficientemente povoado por bons objetos, portanto, depende da invulnerabilidade do bom objeto interno - que para nós representa o manancial de experiências de confiança e segurança que vão propiciar ao ego a capacidade de atravessar, de forma satisfatória, perdas, traumatismos e lutos.

Esse mundo de bons objetos internalizados pode ser pensado também como o conjunto de todas as vozes e memórias das experiências de satisfação, proteção e confiança vivenciados desde o período mais arcaico da existência. Vozes que constituem o psiquismo, dotando-o de capacidades, fortalecendo-o e expandindo-o a cada nova experiência de ruptura e perda. Essas vozes só se formam ao ter passado pelo processo de apropriação subjetiva, precisam ter se convertido, através de simbolizações sucessivas, em uma capacidade de se sentir e de sentir o outro, de se ver e de ver o outro, de se ouvir e de ouvir o outro. Trata-se de um infindável processo de construção e afinação que se dá através da elaboração da posição depressiva e da dissolução do complexo de Édipo, as quais permitem a entrada no regime do Princípio de Realidade, e na consciência da transitoriedade de tudo. São tais sucessivas elaborações que permitem conquistar a capacidade de fazer uma experiência e de aprender com a experiência.

Em todo processo de luto, deve haver a aceitação de uma morte e algum tipo de renascimento. Lembramos que o desmame é a primeira perda grande e significativa capaz de ressignificar a cesura do nascimento, conforme Klein defende no texto de 1940. Essa experiência, que provocará importantes mudanças psíquicas, será o ponto de partida para que se estabeleça a aceitação de que, a partir desse momento, continuamente existirá algo a ser perdido e algo a ser conquistado. Perde-se a etapa da amamentação para que, através da própria perda, constitua-se 
um mundo interno que permitirá viver fora do aleitamento e da dependência absoluta em relação à mãe. Renuncia-se a um lugar, a algo ou a alguém; são milhares de pequenas mortes que permitem passar de um estágio a outro, como se cada perda funcionasse como um vislumbre de uma ponte que nos leve a outro lugar, que nos permita o acesso a algo novo.

Klein (1940/1996) afirma que as pessoas adoecidas de melancolia ou estados maníaco-depressivos, ou ainda as que atravessam um luto anormal, têm em comum o fracasso na sua capacidade de fazer lutos, o que nos faz pensar que não conseguiram estabelecer dentro de si seus objetos bons internos. Isto impossibilitou a instalação de um sentimento forte de segurança e o enraizamento de uma capacidade de transformação da dor e da perda em seu mundo interno, ou seja, não chegaram a superar a posição depressiva infantil.

Depreendemos dos postulados kleinianos, portanto, que, para atravessar de forma suficientemente satisfatória os primeiros lutos, decorrentes da entrada na posição depressiva infantil, é preciso que aconteça a firme introjeção dos bons objetos internos. Essa experiência primordial de trabalho de luto cria um espaço psíquico de contenção e elaboração, para que outros tantos processos de luto possam ser suportados e elaborados ao longo de toda a vida. Essa introjeção dos bons objetos internos cria um espaço psíquico, que Pontalis (2005) dizia ser a presença da mãe ausente, como solo em que a subjetividade vai ser construída. Para Klein (1940/1996), o bom objeto interno vai além da mãe: ele se forma pela introjeção de um casal parental em harmonia. Klein propõe que os bons cuidados maternos dependem da existência de uma mulher feliz, em quem predomina uma dinâmica amorosa. Essa dinâmica, embora tenha suas raízes arcaicas na própria relação de objeto que aquela mulher teve com a sua mãe, precisa, no momento em que se torna mãe, ser sustentada e alimentada pelo relacionamento com um homem que a situe como mulher, e faça da criança que tiveram, a manifestação de um amor ao mesmo tempo sexual e terno, dando-lhe uma origem que não a define como produto apenas da mãe.

Do sucesso do trabalho do luto depende a reconstrução do mundo interno do indivíduo e a reinstalação no ego de bons objetos internos, que são não somente os objetos perdidos no momento atual, mas todos os objetos perdidos e transformados em bons objetos internos desde a infância mais arcaica. Uma elaboração de luto bem-sucedida pode ser o ponto de partida, em muitos casos, para o despertar da criatividade científica, artística e literária.

A reinstalação dos bons objetos internos (...) produz um sentimento de renovação que está associado à recuperação da capacidade de amar, interessar-se e investir no mundo depois da longa hibernação do luto. É isso, fundamentalmente, o que o melancólico e o deprimido não conseguem fazer. (Cintra \& Figueiredo, 2004, p. 101) 


\section{LITERATURA, PSICOPATOLOGIA}

Voltando a Oscar Wilde, é possível supor que, em decorrência das vivências traumáticas, desde a sua exposição e humilhação pública durante o julgamento e condenação, passando pelo sofrimento da prisão e, depois, ao descobrir-se inteiramente destituído de sua capacidade de criar, ele não tenha sido capaz de elaborar psiquicamente todas as perdas sofridas.

A partir de uma interpretação dos textos que relatam a experiência de Wilde antes e depois da prisão, podemos supor que, pela magnitude do trauma sofrido, ele deve ter experimentado uma quebra demasiado intensa de sua potencialidade criativa. Um trabalho psíquico de transformação das vivências traumáticas em uma nova forma de subjetividade ficou impossibilitado.

Condenado a uma vida nas sombras, justamente ele, considerado o apóstolo da beleza, aquele cujo projeto maior de vida era transformá-la numa verdadeira obra de arte, e defensor do florescimento individual como forma máxima de expressão da própria personalidade, percebe-se incapaz de reconstruir seu mundo interno e externo. Impedido de ver os próprios filhos e vivendo na miséria, Oscar Wilde fenece definitivamente, sem conseguir libertar-se dos fantasmas que imobilizaram sua criatividade artística literária.

Em vários momentos nos textos de 1935 e 1940, Melanie Klein nos fala da capacidade de amar e reparar, que é despertada e desenvolvida à medida que a criança pequena entra na posição depressiva. Acreditamos que sobretudo a capacidade de fazer reparação é um importante mecanismo entre muitos outros adquiridos após a elaboração da posição depressiva infantil.

Por ora, queremos lembrar que são muitas as capacidades desenvolvidas pela entrada e elaboração da posição depressiva, capacidades que são renovadas e ampliadas a cada novo trabalho psíquico realizado. Entre tantas, devemos destacar que se cria uma sensibilidade moral e ética que está intimamente relacionada à capacidade de se preocupar com o outro, de sentir empatia por ele. Devemos abrir mão da nossa onipotência, o que significa aceitar os próprios limites, além de reconhecer que o desejo de satisfação plena não é possível. O veredicto da realidade obriga-nos, a todo instante, a nos despedirmos do momento atual para acessar o momento seguinte.

Desenvolvemos, assim, maior tolerância à frustração e, com isso, a capacidade de esperar, pois somos capazes de reconhecer que todos os estados de ser são transitórios. Tudo isso, é claro, envolve a capacidade de conter e elaborar a realidade psíquica, discriminando a vida de fantasia da realidade. Isto, nos parece inegável, é trabalho para uma análise inteira, e por que não considerar para uma vida inteira? 


\section{Referências}

Cintra, E.M.U., \& Figueiredo, L.C. (2004). Melanie Klein, estilo e pensamento. São Paulo: Escuta.

Ende, M. (2010). A história sem fim. (9. ed.). São Paulo: Martins Fontes.

Hinshelwood, R. D. (1992). Posição depressiva. In Dicionário do pensamento kleiniano. Porto Alegre: Artes Médicas.

Hinshelwood, R. D. (1992). Posição esquizoparanoide. In Dicionário do pensamento kleiniano. Porto Alegre: Artes Médicas.

Klein, M. (1996). Uma contribuição à psicogênese dos estados maníaco-depressivos. In M. Klein, Amor, culpa e reparação e outros trabalhos (1921-1945) (pp. 301-329). Rio de Janeiro: Imago. (Trabalho original publicado em 1935).

Klein, M. (1996). O luto e suas relações com os estados maníaco-depressivos. In M. Klein, Amor, culpa e reparação e outros trabalhos (1921-1945) (pp. 385-411). Rio de Janeiro: Imago. (Trabalho original publicado em 1940).

Pontalis, J.-B. (2005). Entre o sonho e a dor. Tradução Cláudia Berliner. Aparecida, SP.: Ideias \& Letras. (Trabalho original publicado em 1975).

Schiffer, D. S. (2011). Oscar Wilde. Porto Alegre: Editora L\&PM.

Vieira, M.R.J. (2014). Oscar Wilde e Dorian Gray: sobre a experiência da perda, da dor e do luto. Dissertação de Mestrado em Psicologia Clínica. Pontifícia Universidade Católica de São Paulo, PUC-SP, São Paulo.

Wilde, O. (2009). De Profundis e outros escritos do cárcere. Porto Alegre: Editora L\&PM. (Trabalho original publicado em 1905).

Wilde, O. (2013). O retrato de Dorian Gray - Ed. Anotada e não censurada. São Paulo: Globo. (Trabalho original publicado em 1890).

\section{Resumos}

(Oscar Wilde's broken mirror)

This article presents some thoughts about the grief process and the challenges that have to be overcome so that mourning may take place and loss may be processed. It is based on the psychoanalytic theory and on some aspects of Oscar Wilde's life that were taken from his biography by Daniel Salvatore Schiffer to cast a light on the inhibition of mourning, which leads to melancholy and the impoverishment of creativity.

Key words: Mourning, melancholy, depressive position, internal object, Klein 


\section{LITERATURA, PSICOPATOLOGIA}

\section{(Le miroir brisé d'Oscar Wilde)}

Cet article présente quelques considérations sur le processus du deuil et de la tristesse, ainsi que sur les défis qui se posent à l'élaboration du deuil et de la perte. Il s'inspire de la théorie psychanalytique et de la lecture sur certains aspects de la vie d'Oscar Wilde, à partir de la biographie de Daniel Salvatore Schiffer, pour élucider le problème de l'inhibition du deuil qui, à son tour, conduit à la mélancolie et l'appauvrissement de la créativité.

Mots clés: Deuil, mélancolie, position dépressive, objet interne, Klein

\section{(El espejo roto de Oscar Wilde)}

Este artículo presenta algunas consideraciones sobre los procesos del duelo y la melancolía, de los desafios que se plantean para la elaboración del duelo y la pérdida. Se inspira en la teoría psicoanalítica y en la lectura de algunos aspectos de la vida de Oscar Wilde, que fueron extraídos de la biografía escrita por Daniel Salvatore Schiffer, para iluminar la problemática de la inhibición del duelo, lo que conduce a la melancolía y al empobrecimiento de la creatividad.

Palabras claves: Duelo, melancolía, posición depresiva, objeto interno, Klein

(Die zerbrochenen Spiegel Oscar Wilde)

Dieser Artikel enthält Überlegungen zum Trauerprozess und zur Melancholie, sowie zu den Herausforderungen, die der Verarbeitung von Trauer und Verlust eigen sind. Wir stützen uns dabei auf die psychoanalytische Theorie und auf einige Aspekte aus Oscar Wildes Leben, die in der von Daniel Salvatore Schiffer verfassten Biographie enthalten sind, um das Problem der Hemmung zu trauern zu beleuchten, welche zu Melancholie und zur Verarmung der Kreativität führt.

Schlüsselwörter: Trauer, Melancholie, depressive Position, internes Objekt, Klein

（奥斯卡・王尔德的破镜子）

本文介绍有关悲痛过程和悲观一些内容和解决悲痛和损失的挑战。它是由 精神分析理论与丹尼尔・萨尔瓦托雷 - 希弗写的王尔德传纪的研究来分析悲哀及 其导致的忧郁和创造能力的贫困化。

关键词: 莫宁, 忧郁, 忧郁的位置, 内部对象, 克莱因 
Citação/Citation: Jacobina Vieira, M.R., \& Cintra, E.M.U. (2015, dezembro). O espelho partido de Oscar Wilde. Revista Latinoamericana de Psicopatologia Fundamental, 18(4), 758-770.

Editor do artigo/Editor: Vários

Recebido/Received: 30.3.2015/ 3.30.2015 Aceito/Accepted: 10.6.2015 / 6.10.2015

Copyright: (C) 2009 Associação Universitária de Pesquisa em Psicopatologia Fundamental/ University Association for Research in Fundamental Psychopathology. Este é um artigo de livre acesso, que permite uso irrestrito, distribuição e reprodução em qualquer meio, desde que o autor e a fonte sejam citados / This is an open-access article, which permits unrestricted use, distribution, and reproduction in any medium, provided the original authors and sources are credited.

Financiamento/Funding: Os autores declaram não terem sido financiados ou apoiados / The authors have no support or funding to report.

Conflito de interesses/Conflict of interest: Os autores declaram que não há conflito de interesses / The authors have no conflict of interest to declare.

\section{Marcus Rodrigues Jacobina Vieira}

Mestre em Psicologica Clínica pela Pontifícia Universidade Católica de São Paulo - PUC-SP (São Paulo, SP, Br)

Rua Áurea, 292 casa - Vila Mariana

04015-070 São Paulo, SP

e-mail:markusrod@yahoo.com.brou marcusjacobina@gmail.com

\section{Elisa Maria de Ulhôa Cintra}

Doutora em Psicologia Clínica pela Pontifícia Universidade Católica de São Paulo PUC-SP (São Paulo, SP, Br); Professora do Programa de Estudos Pós-Graduados em Psicologia Clinica da PUC-SP.

Rua Vargem do Cedro, 201/112

01252-050 São Paulo, SP

e-mail: elcintra01@gmail.com

\section{(cc) BY-NC}

This is an open-access article, which permits unrestricted use, distribution, and reproduction in any medium for non-commercial purposes provided the original authors and sources are credited. 